\title{
Violência simbólica e redes sociais no facebook: o caso da fanpage "Diva Depressão"1
}

Raquel Recuero

Pricilla Soares

Resumo: O presente artigo foca a violência simbólica e sua propagação através do discurso em sites de rede social. O objetivo é discutir os mecanismos através dos quais o estigma social é exposto e reforçado no Facebook, através do conteúdo publicado por fanpages humorísticas. Para trazer evidências para esta discussão, apresentamos dados de uma fanpage popular, "Diva Depressão" e analisamos três postagens e seus comentários através da Análise do Discurso Mediado pelo Computador (CMDA). Os resultados apontam para evidências de que tanto o conteúdo das páginas quanto as interações (comentários, curtidas e compartilhamentos) reforçam e naturalizam o estigma.

Palavras-chaves: violência simbólica; estigma; redes sociais na internet; Facebook; análise do discurso mediado por computador

Abstract: Symbolic violence and social networks on Facebook: The "Depression Diva" fanpage case - This paper focuses on symbolic violence and discourse on social network sites. We discuss some of the mechanisms through which social stigma is exposed and reinforced on Facebook, focusing on fanpages dedicated to humorous content. To support the discussion we present a qualitative study with one case study of a popular fanpage, "Depression Diva", from which posts and comments are analyzed. Results show evidences that both the content of the pages and the interactions (comments, likes and shares) reinforce and naturalize stigmas.

Keywords: symbolic violence; stigma; online social networks; Facebook; computer mediated discourse analysis

\footnotetext{
1 Artigo realizado com o apoio do Programa Pesquisador Gaúcho da FAPERGS (PqG 2012 - processo nº 12/1878-5).
} 


\section{Introdução}

There are no longer any innocent words.

(Bourdieu 1991, p. 40)

O crescimento do uso do Facebook, no Brasil, ${ }^{2}$ nos últimos anos, trouxe novos contextos para os processos de comunicação e para os discursos. Esses novos contextos permitem também que novas e antigas práticas sociais emirjam e se popularizem nas redes sociais on-line. Este artigo busca explorar uma dessas práticas: o uso do Facebook como ferramenta de violência simbólica, onde o discurso reproduzido é capaz de perpetuar o estigma social e dar-lhe novos contornos. Para esta discussão, escolhemos focar uma fanpage ${ }^{3}$ de conteúdo humorístico bastante popular no Facebook, a "Diva Depressão". A hipótese que guia o trabalho é a de que o humor nos discursos da fanpage ajuda a mascarar uma violência objetiva, travestindo-a. Ao mesmo tempo, as características de público em rede do próprio Facebook contribuem para amplificar o discurso e legitimá-lo.

\section{Violência, estigma e humor}

O conceito de violência é discutido por muitos autores. Benjamim, em seu trabalho Critique of Violence (1999), explica que, para alguns autores, a violência é um "produto da natureza", no sentido de que está intrínseca à humanidade; e, para outros, um "produto da história", que não é, portanto, natural ao homem, mas um produto do desejo pela dominação (ibid., p. 243). Neste trabalho, interessa-nos o conceito de violência simbólica, que é aquela que advém da linguagem. É um produto das relações históricas de dominação nos espaços sociais, que passa a residir também nos espaços on-line.

Žižek (2008) entende a violência a partir de uma trilogia. Há uma forma mais visível, mais evidente, que compreende as explosões de violência que chamam a atenção das pessoas. É o caso, por exemplo, de atentados, revoltas, etc. Essa é a forma subjetiva de violência. Há outra forma, menos evidente, mais intrínseca na estrutura social, a violência objetiva. Esta está imbuída na percepção cotidiana de normalidade, no dia a dia e tem duas formas: a simbólica e a sistêmica. A violência simbólica é aquela que acontece através da linguagem, das imposições discursivas. A violência sistêmica, por outro lado, é uma consequência do sistema político e econômico, está nas estruturas sociais. Uma tem o papel de reforçar a outra. A lógica do capital impõe e interpõe os sentidos que são construídos e que reforçam as estruturas sociais reproduzindo as relações de dominação.

2 O Facebook, hoje, congrega mais de 65 milhões de usuários brasileiros, e o Brasil contabiliza a segunda maior população dos mais de um bilhão de usuários da ferramenta no mundo (Fonte: Social Bakers, 2012)

3 Uma fanpage é uma página que pode ser criada por qualquer usuário no Facebook e que é, normalmente, direcionada a algum tipo de conteúdo específico. Outros usuários podem tornar-se "fãs" e assim receber o conteúdo publicado pela fanpage. 
Bourdieu $(1989,1991)$ vê a violência simbólica como resultado do poder simbólico, reforçando a imposição dos sentidos e a naturalização das relações de poder. É, portanto, resultado também da imposição da ideologia através do discurso. Para Bourdieu (1991), o poder simbólico pressupõe o «não reconhecimento da violência que é exercida através dele $^{\prime \prime 4}$ (ibid. p. 209). Com isso, ele caracteriza também a violência simbólica como uma violência silenciosa, porque suas vítimas não se reconhecem como vítimas, já que falham em identificar a própria violência como tal. Trata-se da naturalização dos sentidos gerados pela dominação, como Žižek também percebe, criada e legitimada pelo discurso.

A violência simbólica tem um importante papel na reprodução dos estereótipos e dos estigmas sociais. Goffman (1963) explica que o estigma constitui as marcas e atributos pelos quais alguém é criticado e marginalizado pela sociedade. O estigma, assim, é uma marca que é construída como «negativa» pelo grupo e que caracteriza a identidade do Outro e da qual este não consegue libertar-se. É uma marca percebida também em relação àqueles que não a possuem, que não são estigmatizados. É como se a sociedade ficasse cega para os outros atributos que determinada pessoa tem, vendo apenas seu traço estigmatizado. Caracteriza, assim, categorias de indivíduos e as especificidades esperadas dessas categorias, através de seus estereótipos negativos.

É justamente na percepção dos estereótipos e no reforço deles que o sentido do humor muitas vezes reside. A graça de uma piada é muitas vezes experimentada diante de características estereotipadas e vistas como negativas dos outros. Assim, uma piada de «português», por exemplo, apenas é engraçada porque fala ao estereótipo associado ao grupo, ao estigma desabonador construído pelo discurso sobre a nacionalidade. Assim, o humor também tem um papel frequentemente associado à violência, conforme discutem Kirsh (2006), Jabloski e Zilmann (1995) e Bicalho et al (2011). Neste último trabalho, os autores inclusive discutem a hipótese de que o humor, muitas vezes, altere o impacto de conteúdos violentos. O humor, assim, pode atuar no discurso de forma a mascarar e reduzir o impacto da violência na percepção dos sujeitos.

Humor é uma categoria polêmica. Crawford (2003) vê o humor como um «modo» do discurso, cujo foco está na interação social. Para a autora, que discute o conceito a partir do trabalho de Mulkay (apud CRAWFORD, 2003), a categoria humor é um modo muito mais aberto do que se pressupõem: O modo "humor" existe em oposição do "modo sério", onde os falantes pressupõem uma realidade objetiva a qual provê o contexto da fala e em cima da qual eles concordam. O humor, assim, compreende toda uma forma de contexto diferenciada para a interação, onde a fala pode ser compreendida a partir de diferentes elementos, tais como a "aceitação da ambiguidade, do paradoxo, das múltiplas interpretações da realidade e da incongruência" ${ }^{5}$ (CRAWFORD, 2003, p. 1420).

4 Tradução para: "symbolic power is a power which presupposes recognition, that is, misrecognition of the violence that is exercised through it".

5 Tradução das autoras para: "acceptance of ambiguity, paradox, multiple interpretations of reality, and partially resolved incongruity". 
Esse conceito, amplo, de humor, assim, compreende todo o contexto onde aquilo que não pode ser dito sob o "modo sério" é então, aceitável. Abrange, assim, todos os textos que trazem como centro a marcação da "graça", seja ela através de qual figura de linguagem for (incluindo aí, a ironia ${ }^{6}$ ).

\section{Redes sociais, sites de rede social e discurso mediado pelo computador}

Os sites de rede social tiveram um impacto profundo no cotidiano das pessoas, alterando a forma como se relacionam, constroem e percebem valores e mesmo como constroem significados e sentidos. Eles não apenas refletem essas redes, mas influenciam sua construção e com isso, os fluxos de informação que circulam nesses grupos (RECUERO, 2012).

Boyd (2010) reflete sobre essa mudança explicando que esses sites constituem um novo tipo de público, o que ela chama de público em rede. Esse público possui propriedades que são características do digital, a saber: a) persistência, ou seja, as informações que são publicadas permanecem oniline; b) replicabilidade, as informações publicadas são facilmente replicáveis (e de forma idêntica ao original); c) escalabilidade, a difusão de informações pode ser escalada dentro das redes, construindo visibilidade; e d) "buscabilidade", que é a capacidade dessas informações serem buscáveis nesses espaços. Essas mudanças refletem as formas de circulação de informação nesses públicos e ocasionam o que a autora chama de "nova dinâmica" dos contextos de interação. Essas características auxiliam a perceber os impactos das apropriações dessas ferramentas no cotidiano dos indivíduos e na circulação de informações nos grupos sociais. Uma vez publicada a informação, portanto, ela torna-se permanente, replicável, buscável e tem sua visibilidade escalada.

Essa nova dinâmica altera o espaço onde o discurso é publicado, reproduzido e significado. Essas alterações seriam (BOYD, 2010): a) a presença de audiências invisíveis, ou seja, o fato de que o discurso não está restrito a audiência percebida do mesmo, mas é reproduzido e repassado na rede; b) colapso dos contextos, que se refere ao fato de que o discurso não tem necessariamente um contexto dividido pelos participantes do processo, e, muitas vezes, é difícil de compreender pela ausência do contexto; c) borramento das fronteiras entre público e privado, que se refere ao fato de que não há fronteira entre os discursos expostos às várias redes sociais, justamente porque essas redes estão mais interconectadas nesses sites. Essas mudanças são importantes porque são decorrentes da hiperconexão entre as redes sociais. Em ferramentas como o Facebook e outros sites de rede social, as práticas sociais que influenciam as conexões (como, por exemplo, a necessidade de ter mais conexões ou a flexibilidade do conceito de «amigo») influenciam também os modos de espalhamento dos discursos entre os grupos sociais.

6 Embora vários exemplos neste trabalho possam ser discutidos sob o ponto de vista do uso da ironia, é importante pontuar que esta, como figura de linguagem, é focada no humor pela "oposição" dos sentidos. 
Herring (2001, p. 612) define o discurso mediado pelo computador como aquela "comunicação produzida quando seres humanos interagem uns com os outros através da transmissão de mensagens pelas redes de computadores" ${ }^{\prime 7}$. Esses discursos, explica a autora, têm efeitos nos sujeitos e são também impactados pelas apropriações desses sujeitos das ferramentas de comunicação. Esses discursos possuem também características linguísticas que são resultados das apropriações e das restrições e possibilidades das ferramentas. Estudar o discurso on-line é estudar a linguagem em uso e a construção de sentidos em ambientes diferentes, mediados e apropriados. E essas apropriações também podem gerar comportamentos diferentes, inclusive violentos e hostis, como a reprodução de formas de agressividade on-line.

\section{Abordagem Metodológica}

Herring (2004 e 2013) defende que o estudo dos discursos on-line deve ser realizado através de uma perspectiva que chama de CMDA - Computer Mediated Discourse Analysis (Análise de Discurso Mediada pelo Computador), cujo foco está na linguagem e na linguagem em uso no ambiente on-line. A proposta foi construída pela autora como uma forma de trazer a perspectiva linguística de estudo do discurso para o ambiente on-line e que nos parece adequada para o estudo a que este trabalho se propõe.

O objetivo é trazer um conjunto de métodos ancorados nas perspectivas de análise linguística do discurso, a partir de um foco híbrido que traz, ao mesmo tempo, diversas disciplinas que abordaram o advento da comunicação on-line.

É importante salientar, entretanto, que a CMDA não se enquadra nas formas tradicionais de estudo do discurso, como a AD (Análise do Discurso de fundo francês) ou a ACD (a chamada Análise Crítica do Discurso). Embora Herring tenha um viés mais focado nesta segunda abordagem, sua proposta de análise busca ser mais abrangente e mais maleável que as abordagens citadas.

A CMDA funciona através de um estudo em quatro níveis de análise, a saber: a estrutura, o sentido, a organização da interação e o fenômeno social. É preciso, assim, mapear esses quatro pontos do fenômeno linguístico, focando-se desde o nível micro até o nível macro do contexto da interação.

7 Tradução das autoras para: "(...) is the communication produced when human beings interact with one another by transmitting messages via networked computers". 


\begin{tabular}{|c|c|c|c|}
\hline Nível & Questões & Fenômeno & Método \\
\hline Estrutura & $\begin{array}{l}\text { Oralidade, formalidade, } \\
\text { eficiência, expressividade, } \\
\text { complexidade, característi- } \\
\text { cas de gênero e etc. }\end{array}$ & $\begin{array}{l}\text { Tipografia, ortografia, mor- } \\
\text { fologia, sintaxe, esquema } \\
\text { do discurso, convenções } \\
\text { de formatação e etc. }\end{array}$ & $\begin{array}{l}\text { Linguística estrutural e } \\
\text { descritiva, Análise textual, } \\
\text { Corpus linguístico, estilís- } \\
\text { tica etc. }\end{array}$ \\
\hline Sentido & $\begin{array}{l}\text { Qual é a intenção } \\
\text { O que é comunicado } \\
\text { O que é realizado }\end{array}$ & $\begin{array}{c}\text { Sentido de palavras, atos } \\
\text { de fala, locuções, trocas } \\
\text { e etc. }\end{array}$ & Semântica e pragmática. \\
\hline Interação & $\begin{array}{c}\text { Interatividade, tempo, } \\
\text { coerência, reparação, } \\
\text { interação como construção } \\
\text { e etc. }\end{array}$ & $\begin{array}{l}\text { Turnos, sequenciamentos, } \\
\text { trocas e etc. }\end{array}$ & $\begin{array}{l}\text { Análise da Conversação e } \\
\text { etnometodologia. }\end{array}$ \\
\hline Comportamento Social & $\begin{array}{c}\text { Dinâmica social, poder, } \\
\text { influência, identidade, } \\
\text { comunidade, diferenças } \\
\text { culturais e etc. }\end{array}$ & $\begin{array}{l}\text { Expressões linguísticas } \\
\text { de status, negociação de } \\
\text { conflito, gerenciamento da } \\
\text { face, jogos, discurso e etc. }\end{array}$ & $\begin{array}{c}\text { Sociolinguistica intera- } \\
\text { cional, Análise Crítica do } \\
\text { Discurso, Etnografia da } \\
\text { comunicação. }\end{array}$ \\
\hline Comunicação Multimodal & $\begin{array}{l}\text { Efeitos do modo, coerência } \\
\text { do cruzamento de modos, } \\
\text { gerenciamento de ende- } \\
\text { reçamento e referência, } \\
\text { espalhamento de unidades } \\
\text { de sentido gráficas, coativi- } \\
\text { dade de mídia e etc. }\end{array}$ & $\begin{array}{l}\text { Escolha do modo, texto- } \\
\text {-na imagem, citações em } \\
\text { imagens, animação, deixis } \\
\text { e posição espacial e tem- } \\
\text { poral, etc. }\end{array}$ & $\begin{array}{l}\text { Semiótica social, análise } \\
\text { de conteúdo visual e etc. }\end{array}$ \\
\hline
\end{tabular}

Tab. 1. Quatro níveis da CMDA:

Fonte: Adaptado de Herring (2004)

Para Herring (2004), cada domínio abrange uma gama de fenômenos e depende de uma codificação específica, que deve ser realizada pelo pesquisador. Embora a inspiração para a análise esteja em cada perspectiva metodológica, ela propõe ações específicas dentro dos quatro níveis para cada fenômeno, baseadas em interpretação dos dados e codificação cuidadosa.

Se os sites de rede social, como o Facebook, criam novos ambientes para os discursos, ambientes multimodais, que possuem as características elencadas por Boyd (2010) dos públicos em rede, faz-se necessário compreender essas mudanças e alterações. Assim, discutir como os discursos reproduzidos no Facebook reconfiguram formas simbólicas de violência através do ambiente e geram efeitos emergentes é o principal objetivo deste trabalho. As questões de pesquisa que guiaram o trabalho, assim, são: Como o conteúdo humorístico no Facebook pode reconfigurar formas de violência simbólica e a reprodução de estigmas? Quais são os mecanismos de reforço e legitimação desses discursos?

Para discutir essas questões, optou-se por focar especificamente em uma fanpage bastante popular no Facebook e que produz conteúdo que é reproduzido e espalhado

8 Essa última categoria é proposta e discutida por Herring em novo trabalho (2012) e não fazia parte das características propostas inicialmente em 2004. A inclusão dessa categoria é proposta diante do advento do que a autora chama de Web 2.0, os novos ambientes do discurso que projetam novos padrões de uso, novos contextos de linguagem, convergentes e hipermidiáticos. 
na rede por centenas (às vezes milhares) de usuários. Optamos assim por analisar postagens publicadas pela fanpage "Diva Depressão" (https://www.facebook.com/ DivaDepressao), que possui mais de 500 mil fãs $^{9}$. Essa fanpage foi escolhida para a pesquisa porque o conteúdo não apenas é extremamente popular, mas também é construído em cima de uma perspectiva humorística e sarcástica que reconstrói formas de violência simbólica.

Para este trabalho, buscamos uma análise inicial qualitativa a partir de um foco em profundidade do discurso de três postagens, escolhidas entre as mais populares (maior número de curtidas, comentários e compartilhamentos) do mês de janeiro de 2013, que serão, a seguir, analisadas ${ }^{10}$ como exemplos desse discurso. Ressalte-se que a amostra, embora limitada, é adequada para as considerações de profundidade da análise que desejamos construir, embora suas observações não sejam generalizáveis pela sua arbitrariedade. Entretanto, o objetivo é estudar esse discurso de forma exemplificativa e não generalizável.

\section{Análise: violência, humor e discurso nas fanpages}

"Diva Depressão" é uma fanpage focada em dizeres de um personagem feminino (a "diva"), que é sarcástica e "deprimida" com certas situações sociais. A maior parte das postagens tem imagem e as imagens têm um tom vintage, sempre em sépia ou preto e branco, na maioria das vezes focando uma mulher jovem de décadas passadas. Os posts coletados na fanpage "Diva Depressão" parecem focar principalmente em elementos de ironia ou sarcasmo sobre o corpo e o comportamento das mulheres. A personagem, nesse contexto de coleta, é uma "diva" rica, bonita, fútil e ácida.

a) Estrutura - O primeiro nível de análise proposto é aquele da estrutura. Para contemplar esse nível, passaremos a descrever as postagens e suas características estruturais. Como se trata de um conteúdo evidentemente multimodal, também observaremos o contexto dentro do qual a imagem é publicada, ou seja, os elementos que o Facebook acrescenta: curtidas, comentários e compartilhamentos.

9 Na época de produção deste artigo: março de 2013.

10 As postagens analisadas neste artigo foram escolhidas dentro de uma amostra de 156 postagens do corpus que a pesquisa recolheu durante o mês de janeiro de 2013. 


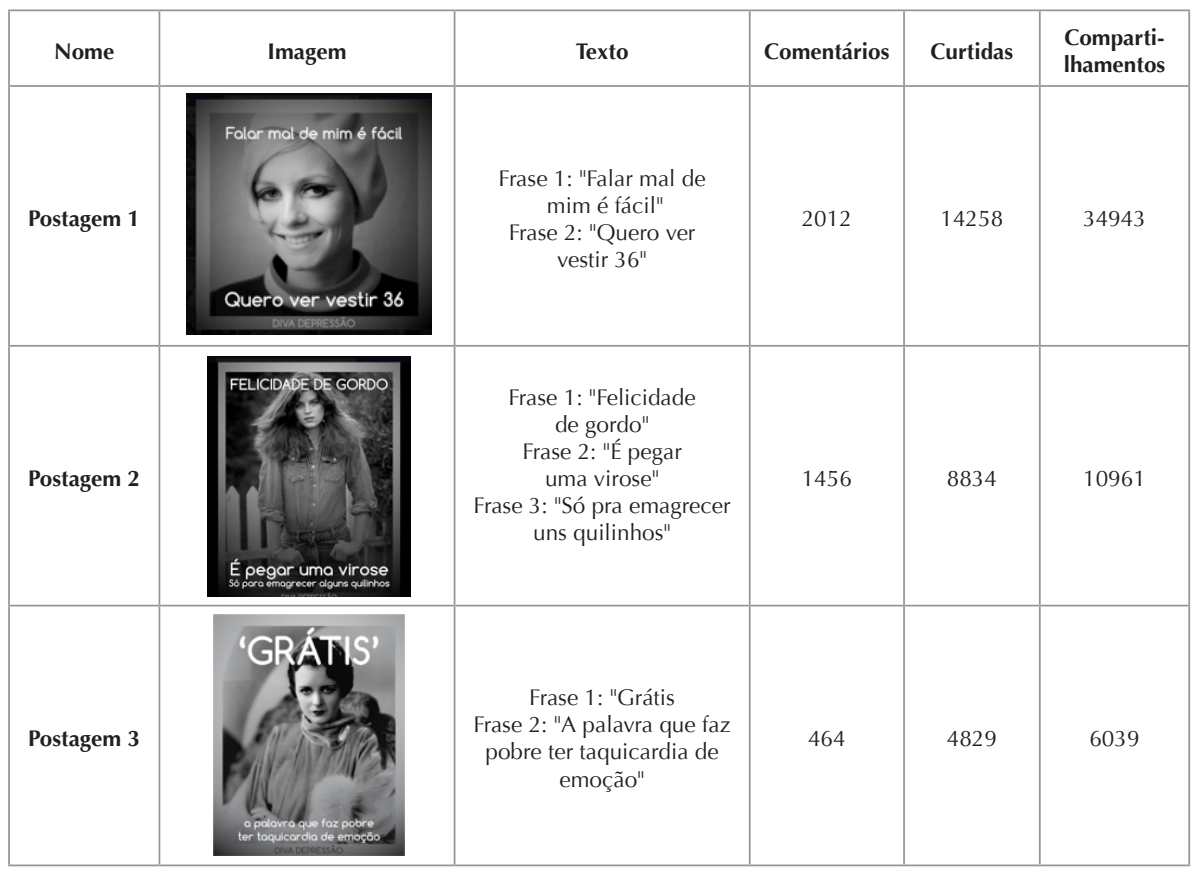

Tab. 2. Sistematização dos dados coletados nas postagens

Como se pode observar na Tabela 2, há bastantes similaridades na estrutura das postagens. Sempre há uma imagem vintage, em preto e branco, representando, nos três casos, uma mulher jovem, magra e bonita. Sobre a imagem há sempre um texto em preto e branco, com um enunciado acima e outro abaixo da foto. O espaço entre os enunciados faz as vezes de pausa, como uma deixa para que o leitor possa compreender o tom sarcástico do texto. Além disso, cada uma dessas postagens possui também um número de compartilhamentos, curtidas e comentários que aparece logo após essa imagem/texto, proporcionado pelo suporte (Facebook). Consideraremos esses como parte da análise porque atuam diretamente na construção de sentido.

b) Sentido - Um segundo nível de análise é aquele do sentido que é construído pela mensagem e sua estrutura. Nos três casos, o sentido evidente é aquele do humor a respeito da mensagem, que salienta um atributo considerado positivo e, ao mesmo tempo, estigmatiza atributos considerados não desejáveis.

No primeiro exemplo, a mensagem constrói a ideia de que os "outros" podem falar mal de mim (a "diva"), construindo a ideia implícita de que o "falar mal" refere-se à inveja 
porque "eu" (a "diva") uso tamanho 36. Tamanho 36, portanto, é almejado por todos, visto como um atributo positivo. Consequentemente, tamanhos maiores constituem um atributo negativo, uma marca, um estigma. Usar tamanhos maiores não é ser "diva", não é estar inserido em um grupo com maior poder na sociedade.

No segundo caso, vemos novamente referência sarcástica ao corpo e aos atributos positivos (magreza) que são desejados por todos, inclusive por aqueles que não têm possibilidades econômicas (os pobres). Aqui, ser rico e magro são os atributos positivados, enquanto ser pobre e gordo são os atributos estigmatizados. Observa-se, portanto, não apenas uma construção de sentido no discurso de estigmatizar o corpo, mas, igualmente, a condição social.

No terceiro caso, a mensagem faz referência direta ao atributo não desejado e negativado (a pobreza) com a mensagem sarcástica a respeito dos bens gratuitos. A condição social é associada ao comportamento inadequado e desprezível dos pobres. Pobre tem "taquicardia" de emoção. Ricos não precisam se preocupar com isso. O capital econômico é um atributo positivo, do qual se depreende a "classe" da "diva", que não se rebaixa ao comportamento negativo, associado àqueles que têm o atributo negativo, como o fato de ser pobre.

É interessante observar o comportamento dos usuários que compartilham as mensagens. Quando um usuário reproduz a mensagem na sua timeline no Facebook, ele toma para si a função de enunciador e o enunciado passa a ser também dele para a sua "audiência invisível" (BOYD, 2010). A mensagem, que pode ser facilmente compartilhada por qualquer um, tem permanência e reprodutibilidade (ibid.). Assim, o usuário pode escolher tornar-se também um emissor, compartilhando a mensagem e tomando para si, também, a fala da "diva". Curtir, compartilhar e comentar também acrescentam sentidos, legitimando ou não o conteúdo da mensagem para as redes sociais de cada sujeito.

c) Interação - A interação, nas postagens, é realizada através das curtidas, compartilhamentos e comentários. Esses três elementos, constituídos pelo suporte da mensagem, interferem na mensagem. Enquanto a "curtida" tem uma carga positiva de legitimação e apoio, é no comentário que pode surgir o questionamento e a discordância.

Nos três casos, entretanto, a maioria dos comentários focou a legitimação da mensagem. No primeiro caso, foram 2012 comentários, onde apenas 356 comentários foram feitos por perfis com identificação masculina. Ou seja, a maioria dos comentários foi feita por perfis com identificação feminina.

Além disso, a maioria dos comentários legitima de alguma forma a mensagem, seja rindo, concordando ou mesmo parabenizando. Alguns comentaristas inclusive explicam que gostariam de publicar a imagem, mas que não o farão porque "seus amigos gordinhos" vão se ofender. (Novamente mostrando que tamanhos maiores que 36 são "gordinhos", e reforçando o estigma.) "kkkk gordinhas, tomem essa!", diz um comentário de perfil 
feminino. Outro comentário feminino reforça "a melhor parte é ver gente dizendo que quem usa 36 é muito magro, mas na verdade quer usar 36 tb!". O estereótipo do "gordo" é a marca do estigma, uma vez que a característica do corpo é construída como negativa e não ideal. Vemos, também, que esses tipos de comentário legitimam o estigma no Facebook, tornando-o natural.

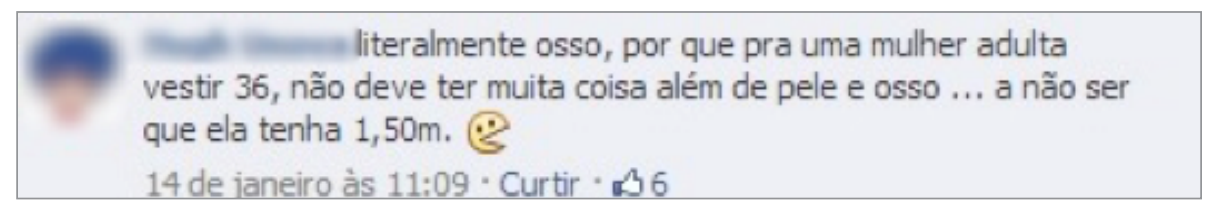

Fig.1. Comentário da postagem 1.

A discordância também aparece nos comentários, mas em número menor (apenas 64 comentários criticavam abertamente o conteúdo da postagem, como na Figura 1). A legitimação dessa discordância acontece através das curtidas. Ao curtir um comentário que discorda, o usuário indiretamente o apoia. Esses comentários, entretanto, geram outros, que os rebatem de forma agressiva (Figura 2) e contribuem também para a visibilidade do discurso que aparece, assim, para outros sujeitos conectados ao comentarista.

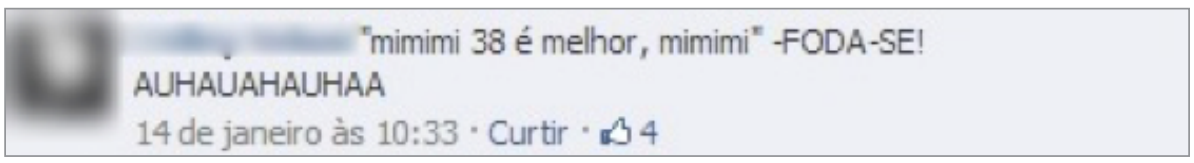

Fig. 2. Comentário da postagem 1.

Na segunda postagem foram coletados 1032 comentários, dos quais 877 eram provenientes de perfis femininos e apenas 145 de perfis masculinos. Apenas 37 comentários fizeram algum tipo de crítica ao post, como no exemplo (Figura 3):

\section{é! \\ 10 de janeiro às $08: 14$ - Curtir \\ Fala sério, ame-se como você}

Fig. 3. Comentário da postagem 2.

Nos demais (995 comentários) vemos a repetição dos comportamentos da análise da primeira postagem, com risos e apoio ao conteúdo publicado. "hahahahaha então elas são felizes e satisfeitas... isso é mentira e hipocrisia ninguém é feliz sendo gordo!" ou "Eu Adorava fikar duente p emagrecer. Huashuash" explicitam comentários de perfis femininos. 
O reforço ao atributo positivo (magreza) e ao negativo que é o estigma (corpo fora do padrão "ideal") é frequente em todas as participações. Ou seja, aqueles que fazem parte do grupo não estigmatizado, ou que veem a postagem apenas como uma forma de humor, predominam e se sentem mais a vontade para se expressar, do que aqueles que não concordam e que não se manifestam por poderem gerar algum tipo de discussão. É o poder simbólico de que fala Bordieu (1989).

No terceiro caso, novamente, entre os comentaristas, há uma maioria de perfis (427) com identificação feminina. Apenas 37 têm identificação masculina. Os comentários, na maioria dos casos (400), reforçam a ideia do atributo "negativado" (no caso, a condição social). "Pobre é uma desgraça, mesmo!", comenta um perfil com identificação masculina. Destaca-se que o enunciado afirma que "pobre" (substantivo, não é "ser pobre") é uma desgraça. Ou seja, a condição econômica não apenas é depreciativa, mas também define o sujeito, estigmatizando-o. Entretanto, em alguns casos, os comentaristas identificam-se com a mensagem, rindo que são "pobres" porque agiram de forma parecida em alguma ocasião. Entretanto, essa identificação é diferente do conteúdo da mensagem. O usuário em geral destaca uma ocasião em que agiu como "pobre" (adjetivo), mas não é, propriamente, "pobre" (substantivo), como nos comentários abaixo (Figura 4), onde ser pobre não é uma condição permanente, e onde o estigma não está marcado porque os indivíduos não se incluem completamente naquela classe, colocando-se apenas em algumas situações como seres que contêm características vistas negativamente.

\section{quando é show de uma banda que eu amo aí o \\ taquicardia é triplo \\ 8 de janeiro às $14: 11$ - Curtir}

Fig. 4. Comentário da postagem 3.

Uma prática interessante observada na interação em todos os casos é aquela de taguear (marcar) amigos nos comentários. Trata-se de uma forma de endereçamento ou direcionamento da mensagem. O amigo recebe a notificação pelo Facebook e vai ver a postagem. Essa prática acontece na maioria dos comentários, geralmente com um objetivo aparentemente humorístico (fazer rir). Entretanto, quando se ri de outrem, o sujeito não é tagueado (Figura 5).

\section{Carla Kkkkk e eu lembrei da Camila que nåo se conforma....kkkkk February 15 at 9:33am via mobile - Like}


Observamos, assim, que a própria interação dentro da conversa das postagens reforça o estigma imposto pelo seu conteúdo, quando os sujeitos se posicionam de forma acrítica e legitimadora do discurso. A conversação, assim, desenvolve-se dentro da proposta do humor, sem discutir os sentidos que são, efetivamente, construídos e legitimados.

d) Multimodalidade - $\mathrm{O}$ suporte do Facebook, por se constituir em um site de rede social e em uma das formas dos públicos em rede, traz implicações para mensagens como esta. O fato de se estar lidando com os chamados "públicos em rede" (BOYD, 2010), cujas características específicas amplificam os impactos desse discurso. Assim, a permanência e a replicabilidade, por exemplo, permite que os sujeitos repassem essas mensagens de modo simplificado e bastante fiel à cópia original, amplificando o discurso e escalando suas reverberações. O discurso pode ser até mesmo alterado, como quando um indivíduo compartilha a postagem, ou a copia e coloca em seu perfil, e a complementa com outro discurso, desconstruindo o tema inicial ou mantendo o estigma e a violência contida nele (Figura 6).

\section{compartilhou a foto de Diva Depressão.}

\section{Inclusive eu!!!}

Curtir ' 14 de fevereiro às $18: 58$ via celular *

\section{2 pessoas curtiram isto.}

Fig. 6. Comentário da postagem 1

Ao mesmo tempo, a possibilidade dos sites de rede social de proporcionarem conexões que são sustentadas apenas pelo on-line, permitindo que os sujeitos as acumulem, também, amplifica o impacto desse discurso. A permanência desse discurso também implica numa ampliação do seu impacto para os sujeitos que participam das redes. As próprias possibilidades de endereçamento descritas acima também alteram a replicação do discurso.

A presença das imagens no texto também constitui outro aspecto da multimodalidade, complexificando a produção de sentidos pelos sujeitos. A imagem do primeiro caso (Tabela 2), da modelo Twiggy, conhecida por sua magreza, reforça o impacto do estigma ou do segundo caso, da atriz Kristy Allen, que notoriamente tem sua luta contra o peso divulgada pela mídia constantemente reforça a mensagem.

e) Comportamento social - Diante dos elementos anteriores, observa-se um reforço e legitimação, através do humor, do estigma. O estigma proposto é aquele do corpo gordo (notadamente o feminino), que é também associado às condições econômicas do sujeito ("pobre"), igualmente qualificadas como atributos negativos ou desprestigiados. 
O discurso que é legitimado é aquele dos atributos do corpo que são considerados positivos (como a magreza e a riqueza) e dignos de inveja e aqueles que, por conseguinte, são negativos e estigmatizantes (a gordura e a pobreza).

O poder simbólico é exercido pelos sujeitos que propagam e que são, ao mesmo tempo, vítimas e agressores da violência simbólica do sentido construído. A violência que é perpetrada pelo discurso estigmatiza ainda mais os atributos indesejáveis do corpo e do "status" social, enquanto legitima aqueles relacionados do poder econômico (riqueza e magreza), e sites de redes sociais como o Facebook, por sua manutenção e troca de contextos, permanência e audiências invisíveis ajudam a fazer com que essa legitimação se propague, ou continue se propagando, muito mais rapidamente, de forma mais explícita e alcançando diferentes grupos sociais do que em ambientes off-line.

\section{As estratégias de reforço do discurso}

Nos três casos estudados verificamos a presença de estratégias de estigmatização, construídas através do discurso mediado pelo computador. Como Goffman (1963) argumenta, vimos que o estigma é baseado nos atributos que os "normais" atribuem aos "não normais". Nos casos estudados, vimos que essa atribuição estava intrinsecamente ligada à percepção do corpo e que esta percepção também é associada ao "status" econômico, como se um fosse dependente do outro. Nessas estratégias, observamos uma estrutura de legitimação do discurso do poder econômico como, também, do poder sobre o corpo.

É importante notar que nessas práticas observamos o processo de construção da violência simbólica, descrito por Bourdieu (1991), onde as vítimas não se reconhecem enquanto vítimas. Elas se percebem enquanto estigmatizadores e não como estigmatizados, mesmo que estejam estigmatizando a si ou ao seu grupo como um todo. A própria ação de tomar pra si a postagem da fanpage e republicá-la, por exemplo, pode ajudar a construir a ideia de que o sujeito, aquele que reproduz o discurso, é a "diva", é o "normal". Outro efeito do discurso é a sua naturalização diante do cotidiano. Ele passa a ser percebido como algo "natural", normal, cuja graça reside no fato de dizer aquilo que os sujeitos gostariam de dizer e comentar para os demais, publicando em seus perfis e repassando as mensagens.

Assim, quais seriam as principais estratégias utilizadas para que o discurso perpetue o estigma nos sites de rede social a partir dos exemplos estudados neste artigo?

a) Permissão de humor - É importante observar que o humor parece ter um papel fundamental na naturalização do discurso violento, reduzindo o seu impacto enquanto violência e suavizando sua ofensa (JABLONSKI e ZILLMAN, 1995). O uso do humor para suavizar a violência simbólica, tornando-a mais aceitável, parece ser uma das estratégias mais importantes observadas nos casos estudados. O humor, a graça, não apenas auxilia a popularizar o discurso, mas também, a naturalizá-lo, reproduzindo e amplificando o poder simbólico. 
Assim, o humor gera uma permissão implícita para que qualquer coisa seja dita e reproduzida sem que esse dito possa ser livremente criticado. Quando, nos casos estudados, algum comentário diferente aparecia, criticando e apontando a violência do post, era rapidamente desacreditado pelos comentários seguintes, que os criticavam e eram legitimados em sua crítica através das curtidas. O humor, aqui entendido como "modo do discurso", através da ironia da mensagem, atua como um disfarce, um véu através do qual a violência simbólica se reproduz através desses conteúdos e das interações dos sujeitos no Facebook.

b) Legitimação pela interação - A legitimação, ou seja, o suporte e a reprodução acrítica do discurso são modos de perpetuação dos estigmas no Facebook. Essas postagens traduzem diferentes níveis de violência simbólica, que é construída a partir da estrutura e do sentido do discurso e se reflete principalmente no nível do comportamento social, conforme vimos na análise. A popularidade dessas mensagens atesta a falência na percepção da violência, enquanto os sujeitos apoiam, legitimam e suportam essa violência através das interações que a ferramenta proporciona. Todos os casos estudados representam mensagens que eram extremamente populares no Facebook, e onde cada "curtida" e cada "compartilhamento" reforça a mensagem violenta. Essas ações são formas de violência simbólica na medida em que dão visibilidade ao discurso como natural e aceitável, nos termos em que Bourdieu (1991) explicita.

c) Descrédito dos críticos - A ridicularização e o descrédito daqueles que criticam o discurso parece ser outra estratégia frequentemente utilizada nessas interações. Conforme os exemplos colocados, quando um usuário parece discordar do post ou chamar a atenção dos demais (exemplos colocados onde outros usuários rebatem os que criticam) para os sentidos construídos, ele é rapidamente desacreditado e criticado por não ter senso de humor. Esse descrédito parece uma estratégia relevante para reduzir a influência daqueles que percebem a violência junto à comunidade. O descrédito foi apontado, por Goffman (1963), como a forma mais importante de estigmatizar alguém.

As três estratégias observadas parecem ser fundamentais para amplificar o estigma e a violência. E o fato de que esta acontece on-line ainda traz outras implicações, conforme discutimos. Com isso, a violência simbólica pode encontrar on-line uma estrutura diferenciada para ser amplificada, justamente por causa da estrutura de redes sociais que a suporta. E com isso, os usuários recebem várias vezes a mesma mensagem. Quanto mais recebem, mais natural o estigma e o estereótipo (Bourdieu 1989, 1991; Goffman 1963).

\section{Apontamentos finais}

Este artigo buscou discutir de forma qualitativa o fenômeno do discurso de humor e da violência simbólica, o estigma e sua replicação no Facebook. Discutimos, baseados 
em evidências qualitativas, de que forma esse discurso se articula e como é percebido pelos usuários em três imagens bastante replicadas na ferramenta, retiradas da fanpage "Diva Depressão".

Através de uma análise do discurso mediado por computador - CMDA (HERRING, 2004 e 2012), analisamos as postagens e os comentários publicados pelos usuários, que interagem com elas. Observamos que há estratégias específicas de redução do impacto da violência, notadamente a legitimação pelas ferramentas que o próprio Facebook oferece, a compreensão de que há uma "permissão do humor" para dizer o que quer e uma ação de desacreditar os comentários críticos por parte dos sujeitos que estão interagindo.

Com isso, a violência é naturalizada pelas redes sociais. Porque ela é naturalizada, torna-se mais e mais sistêmica dentro da sociedade, conforme apontou Žižek (2008), legitimando o status quo e tornando-se invisível. O ambiente on-line permite, por meio da conversação entre os indivíduos e sua permanência na reprodução de estereótipos, que a legitimação da violência simbólica se dê mais facilmente e se replique na mesma rapidez em que é legitimada. É importante observar ainda que este artigo traz considerações a respeito de exemplos qualitativos, que precisam ainda ser discutidas diante de uma amostra maior dessas mensagens.

Raquel Recuero é professora e pesquisadora do Programa de Pós Graduação em Letras da Universidade Católica de Pelotas.

raquel@raquelrecuero.com

Pricilla Soares é mestranda do Programa de Pós Graduação em Letras da Universidade Católica de Pelotas.

pricillafsoares@gmail.com

\section{Referências}

BENJAMIN, Walter (1999). "Critique of Violence". In: BULLOCK, Marcus; JENNINGS, Michael W. Selected Writings. Cambridge, Harvard University Press, vol. 1.

BICALHO, Renata Almeida; DINIZ, Ana Paula R; CARRIERI, Alexandre Pádua; SOUZA, Mariana Mayumi Pereira de (2011). Symbolic Violence and Homosexuality: A Study in Brazilian Major Cities. Far East Journal of Psychology and Business, n. 5, v. 1. Disponível em:<www.fareastjournals.com/ files/FEJPBV5N1P1.pdf>. Acessado em mar. 2013.

BOURDIEU, Pierre (1989). O Poder Simbólico. Rio de Janeiro, Bertrand Brasil. 
BOYD, Danah (2010). "Social Network Sites as Networked Publics: Affordances, Dynamics, and Implications". In: PAPACHARISSI, Zizi (ed.). Networked Self: Identity, Community, and Culture on Social Network Sites. Routledge, pp. 39-58.

CRAWFORD, Mary (2003). Gender and humor in social context. Journal of Pragmatics, 35.

GOFFMAN, Erving (1963). Stigma. Notes on the Management of Spoiled Identity. New York, Touchstone.

HERRING, Susan C. (2001). "Computer-mediated discourse". In: Schiffrin, Deborah; TANNEN, Deborah; HAMILTON, Heidi E. (eds.). The Handbook of Discourse Analysis. Oxford, Blackwell Publishers, p. 612-634. Disponível em: <http://ella.slis.indiana.edu/ herring/cmd.pdf >. Acessado mar. 2013

(2004). "Computer-mediated discourse analysis: An approach to researching online behavior". In: BARAD, Sasha; KLING, Rob; GRAY, James J (eds.). Designing for Virtual Communities in the Service of Learning. New York: Cambridge University Press, pp. 338-376. Disponível em: <http://ella.slis. indiana.edu/ herring/cmda.pdf>. Acessado em mar. 2013.

(2013)." Discourse in Web 2.0: Familiar, reconfigured, and emergent". In: Georgetown University Round Table on Languages and Linguistics 2011: Discourse 2.0: Language and new media. Washington, Georgetown University Press, pp. 1-25. Disponível em: <http://ella.slis.indiana. edu/ herring/GURT.2011.prepub.pdf>. Acessado em mar. 2013.

JABLONSKI, Cynthia King; ZILLMANN, Dolf (1995). Humor's role in the trivialization of violence. Zeitschrift für Medienpsychologie, v. 7, n. 2, jun.

RECUERO, Raquel (2012). A Conversação em Rede. Porto Alegre, Sulina.

ŽlŽEK, Slavoj (2008). Violence: Six Sideways Reflections. London, Profile Books. 